\title{
NORM INEQUALITIES INVOLVING MATRIX MONOTONE FUNCTIONS
}

\author{
M. SINGH AND H. L. VASUdEVA
}

Abstract. Let $A, B, X$ be complex matrices with $A, B$ Hermitian positive definite and let $f$ : $(0, \infty) \rightarrow(0, \infty)$ be matrix monotone increasing. We prove

$$
(2+t)\|\| A^{\frac{1}{2}}\left(f(A) X f^{\perp}(B)+f^{\perp}(A) X f(B)\right) B^{\frac{1}{2}}\|\leqslant 2 \quad\| A^{2} X+t A X B+X B^{2} \|
$$

and

$$
(2+t)\|\| f(A) X+X f(B)\|\| \leqslant 2 \frac{f(\lambda)}{\lambda}\left\|A^{\frac{3}{2}} X B^{-\frac{1}{2}}+t A^{\frac{1}{2}} X B^{\frac{1}{2}}+A^{-\frac{1}{2}} X B^{\frac{3}{2}}\right\|
$$

where $f^{\perp}(x)=x(f(x))^{-1}, t \in[-2,2]$ and $\lambda=\min \{\sigma(A), \sigma(B)\} ; \sigma(A), \sigma(B)$ being the spectrum of $A, B$ respectively and $\| \mid$. $\| \mid$ any unitarily invariant norm. These inequalities generalize Zhan's inequalities.

Mathematics subject classification (2000): 47A63, 15A42.

Key words and phrases: Matrix inequalities, Hadamard product, unitarily invariant norms inequalities.

\section{REFERENCES}

[1] T. ANDO, R. A. HoRn AND C. R. Johnson, The singular values of the Hadamard product: A basic inequality, Linear Multilinear Algebra, 21 (1987), 345-365.

[2] R. BHATIA, Matrix Analysis, Springer-Verlag, New York, 1997.

[3] R. Bhatia AND C. DAVIS, More matrix forms of the arithmetic-geometric mean inequality, SIAM J. Matrix Anal. Appl., 14 (1993), 132-136.

[4] R. BHATIA AND F. KITTANEH, On the singular values of a product of operators, SIAM J. Matrix Anal. Appl., 11 (1990), 272-277.

[5] R. Bhatia And K. R. Parthasarthy, Positive definite functions and operator inequalities, Bull. London Math. Soc., 32 (2000), 214-228.

[6] T. FURUTA, A note on the arithmetic-geometric mean inequality for every unitarily invariant matrix norm, Linear Algebra Appl., 208/209 (1994), 223-228.

[7] D. JociC AND F. KITTANEH, Some perturbation inequalities for selfadjoint operators, J. Operator Theory, 31 (1994), 3-10.

[8] F. KITTANEH, A note on arithmetic-geometric mean inequality for matrices, Linear Algebra Appl., 171 (1992), 1-8.

[9] M. K. KwONG, On the definiteness of the solutions of certain matrix equations, Linear Algebra Appl., 108 (1988), 177-197.

[10] M. K. KWONG, Some results on matrix monotone functions, Linear Algebra Appl., 118 (1989), $129-153$.

[11] X. ZHAN, Inequalities for unitarily invariant norms, SIAM J. Matrix Anal. Appl., 20 (1998), 466-470. 